\title{
EL ÁGUILA: SÍMBOLOS Y CREENCIAS
}

\author{
por \\ XOSÉ RAMÓN MARIÑO FERRO
}

Por su parecido con un águila es por lo que la constelación Águila recibe ese nombre. Dice Webb: "Tenemos el hecho curioso de que en todo el cielo difícilmente encontramos un grupo como éste, al que tantos pueblos hayan dado el mismo nombre". "Las tres estrellas centrales, la brillante Altair y las vecinas que tiene a cada lado, constituyen uno de los grupos más notables del cielo, $\mathrm{y}$, para las gentes acostumbradas a ver remontarse a un águila, guardaban semejanza con un águila en vuelo"1.

Es un ave fuerte y valerosa. Eliano pondera su valentía ${ }^{2}$. En la fábula del pavo real ante Juno, ésta otorga a ese animal la belleza y al águila la fuerza $^{3}$. Invencible para las demás aves, se convierte en símbolo de la VICTORIA. Según Chevalier, "ya en la época de los Medas y de los Persas simbolizaba la victoria". "La cultura romana imperial vio en el águila un pájaro glorioso, emblema de su triunfo universal sobre las demás naciones"4.

Como símbolo de poder y victoria pasó a estar representada en los estandartes de las legiones romanas ${ }^{5}$. Dice Plinio $-\mathrm{y}$ según parece dice

\footnotetext{
${ }^{1}$ Webb 85, 87. Por razon de espacio la BIBLIOGRAFÍA será incluida en un próximo artículo.

2 Eliano XV, 22.

${ }^{3}$ Fedro pág. 74.

${ }^{4}$ Sebastián 41; Toynbee 241; ver Etimologías XVIII, 2, 5.

${ }^{5}$ Hall 30.
} 
bien - que fue C. Marius, durante su segundo consulado, quien estableció el águila como único emblema de las legiones romanas; hasta entonces compartía ese honor con el lobo, el minotauro, el caballo y el jabalí́.

Instala su nido en lugares altos: "Los nidos están situados en paredes de piedra verticales. Desde esa posición se puede vigilar un gran territorio"7. Costumbre que ya aparece señalada en la Biblia. En el libro de Job, por ejemplo, leemos: “¿Por orden tuya se remonta el águila y coloca su nido en las alturas"8. Aristóteles también la menciona: "Las águilas hacen su nido, no en los llanos, sino en los lugares elevados, especialmente sobre rocas escarpadas". En el Libro de las utilidades de los animales se dice que "el águila anida en los sitios más altos y alejados"10.

Puesto que el águila —como luego veremos- representa al príncipe, "el águila que tiene su nido en un alto risco significa - nos dice Covarrubias- el PRÍNCIPE RETIRADO, que no da audiencia a sus vasallos. El águila sentada sobre una peña, y otras aves le dan tornos a la redonda, como que la quieren picar, especialmente las cornejas, significa el MAGNÁNIMO y generoso, que hace poco caso de los denuestos de la gente vil".

Es ave que vuela a gran altura. "Vuela muy alto, con el fin de abarcar con la vista la mayor extensión posible; y por esta razón se dice comenta Aristóteles - que el águila es el único de los pájaros que es divino"11. De las águilas dice Eliano que "surcan el aire superior con alas ligerísimas"12. En una fábula de Odón el águila destaca entre sus méritos su capacidad para el vuelo alto: "Entre otras innumerables virtudes mías, puedo cruzar gracias a mis alas los espacios celestiales volando más alto que cualquier otra ave"13. El Bestiario de Oxford dice: "Se eleva en los aires y se cierne encima de los mares tan alta que permanece invisible a la mirada humana".

Esa capacidad para elevarse en el cielo más que ninguna otra ave le valió para convertirse en atributo de ZEUS, "el dios del cielo diurno" 14. Zeus la eligió para sí al repartirse los dioses las aves ${ }^{15}$. Y la hizo porta-

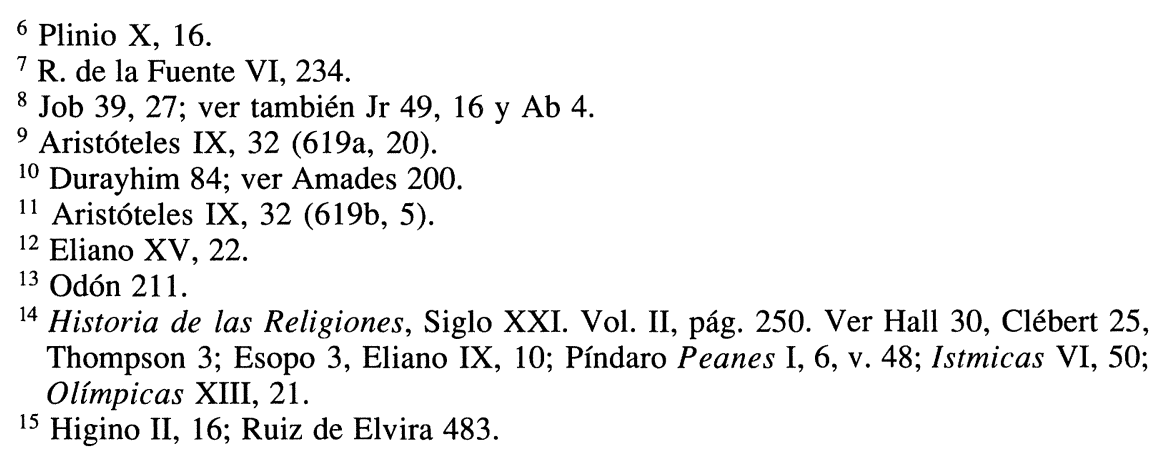

"CUADERNOS DE ESTUDIOS GALLEGOS", Tomo XXXIX, Fascículo 104, Santiago 1991. 
dora de su rayo ${ }^{16}$. El rayo no la hiere: "Se dice —asegura Plinio- que este pájaro es el único al que no mata el rayo; de ahí la tradición que le hace llevar el rayo de Júpiter" 17 .

Por elevarse hacia el cielo "el águila es — dice San Jerónimo- emblema de la ASCENSIÓN y de la ORACIÓN"18. También por esa razón intervenía en la Apoteosis o deificación de los emperadores romanos: "La ceremonia incluía la liberación de un águila que llevaba su alma al cielo, en forma parecida a como Ganimedes fue llevado al Olimpo por el águila de Júpiter"19. Con el cristianismo ese águila pasó a simbolizar a CRISTO, que lleva las almas de la tierra al cielo; la asimilación se basó en este pasaje del Deuteronomio: "Como un águila incita a su nidada, revolotea sobre sus polluelos, así él despliega sus alas y le toma, y le lleva sobre su plumaje"20.

Por la altura de su vuelo, por su aspecto majestuoso, por su fuerza y valentía, ya desde antiguo fue considerada reina de las aves ${ }^{21}$. En la fábula del gavilán y las palomas del Predicador Odón, estas últimas, buscando un jefe que las defienda, piensan: "El águila con su cabeza erguida y su enorme tamaño, es el ave más indicada para tal cargo" 22 . En la fábula del cuclillo y otros pájaros, atribuida a Rómulo, de común acuerdo todas las aves "nombraron rey al águila, pues la juzgaron digna de mando por su tamaño, por su fuerte pico y por sus garras, considerándola un buen defensor ante los ataques de los enemigos, justa, fuerte y severa, de buen temple y poco aficionada a hostigar a sus súbditos con vanas rapiñas. El águila, en efecto, una vez calmada el hambre, ayuna durante varios días y sabe bien que no conviene a la dignidad real oprimir al pueblo con continuas vejaciones"23.

Las mismas características que le valieron el título de reina de las aves la convirtieron en símbolo del REY y del EMPERADOR. Según Horapolo, en Egipto el águila era símbolo del rey ${ }^{24}$. Simbolismo que recogen Valeriano y Capccio ${ }^{25}$. En los emblemas de Solórzano, Juan de Borja,

${ }^{16}$ Cicerón De divinatione I, 47, 106; Virgilio Eneida V, 255; Horacio Odas IV, 4, 1; Ovidio Fastos, 732; Plinio X, 15; Séneca Naturales quaestiones 32; Marcial Epigrammas LV; Neckam pág. 222; Covarrubias; Núñez de Cepeda 176.

${ }^{17}$ Plinio X, 15; Ver Cantimpré 29, Covarrubias.

18 Cirlot 57.

${ }^{19}$ Hall 47.

${ }^{20}$ Dt 32, 11; Sebastián 41.

${ }^{21}$ Vida de Esopo, 91; Plinio X, 6; ver Sebastián 40.

22 Odón pág. 158; ver pág. 211.

${ }^{23}$ Rómulo pág. 230; ver María de Francia 1989, XXXVI; Cantimpré, El Fisiólogo, Guillaume Le Clerc, Philippe de Thaûn, Mugarza I, 130.

${ }^{24}$ Horapollo II, 56; Thompson 4.

25 Valeriano XIX; Capaccio II. 
Diego Saavedra y Núñez de Cepeda se representa el príncipe por un águi$\mathrm{la}^{26}$.

Desde Roma el águila no ha dejado de representar el poder imperial. En la Edad Media el Imperio también fue representado por un águila de dos cabezas. "Afirman algunos autores que la figura del águila de dos cabezas la creó Constantino el Grande, queriendo demostrar con ello que el elegir a Bizancio para capital de su Imperio no implicaba de ningún modo la división de sus territorios. Otros historiadores presumen que la Casa de Habsburgo fue la primera en usar de estas armas"27. Según Covarrubias, "el águila con las dos cabezas significa el uno y otro Imperio, Oriental y Occidental; y éstos le pronosticaron a Alejandro Magno las dos águilas que aparecieron imperiales". "Otra águila doble, la rusa de los zares, simboliza la constitución a un tiempo europea y asiática de aquel imperio, la ambición de recoger la herencia de Constantino"28.

En la empresa de Maximíliano II de Austria aparece un águila bicéfala con una rama de laurel y un haz de rayos. En sus comentarios a esa empresa Ruscelli dice que Nerón hizo acuñar un águila con las alas abiertas, teniendo un pie sobre el rayo y una rama de laurel a su lado derecho, con lo que quiso demostrar su potestad, tanto para declarar la guerra, arruinando así el mundo, como para mantener la paz. A partir de ese precedente, repitieron la imagen otros emperadores, como Vespasiano, Domiciano e incluso Carlos V, que le añadió la inscripción Quique suum, para denotar la justicia del emperador, capaz de premiar la virtud y de castigar el vicio ${ }^{29}$. En el emblema XLV de Núñez de Cepeda aparece un águila con un haz de rayos y una copa para significar el castigo y la clemencia que deben ser sabiamente combinados por el prelado.

Por ser la más destacada de las aves -que se caracterizan por vivir en el aire- pasó a ser símbolo del elemento AIRE. Como tal aparece en la primera escena de La vida es sueño de Calderón.

El águila pescadora se eleva y, una vez descubierta una presa, se zambulle en el agua para capturarla. "A veces se zambulle con tal violencia que desaparece completamente bajo el agua" 30 . Por eso para el autor del Bestiario de Oxford el águila simboliza "la ENCARNACIÓN de Nuestro Señor atravesando las profundidades para volver a subir al cielo". Para Philippe de Thaün, el águila es CRISTO que viene desde lo alto a coger las almas de los hombres como el águila coge peces.

\footnotetext{
${ }^{26}$ Solórzano VIII, Borja 97, Saavera.

${ }^{27}$ Cascante 207.

${ }^{28}$ Cascante 208.

${ }^{29}$ García Mahiques 177; Covarrubias 56.

${ }^{30}$ Burton.
} 
San Isidoro en sus Etimologías dice: "Cuando se mantiene inmóvil sobre los mares sostenida por sus alas a una altura que no es visible al ojo humano, ella desde tan elevada altura ve nadar a los pececillos, sobre los que se precipita a manera de un rayo" 31 . Esta característica de su comportamiento se aprovechó en la Edad Media para representar la purificación por medio del fuego y del agua: el ave asciende tan alto en el cielo que se quema bajo los rayos del sol e inmediatamente desciende para sumergirse en el agua, de la que sale rejuvenecida. (En la cultura tradicional, basándose en la imagen paulina que identifica lo viejo con el pecado, es común significar la renovación moral o espiritual por medio del rejuvenecimiento físico) ${ }^{32}$. Escribe Pierre de Beauvais: "El Fisiólogo afirma que el águila posee una naturaleza tal que cuando envejece, sus alas se vuelven pesadas, su ojo se oscurece y se llena de humor, busca una fuente y se eleva en el cielo en dirección al sol. Allí consume sus alas y quema la inflamación de sus ojos con los rayos del sol. Inmediatamente, desciende hacia la fuente y se sumerge por tres veces.De pronto, sus alas rejuvenecen, sus ojos se aclaran, y se vuelve tan joven como en otro tiempo e incluso más". Guillaume Le Clerc, Latini y el Bestiario de Oxford dicen más o menos lo mismo.

Esa renovación por medio del fuego y del agua sirvió como símbolo del BAUTISMO y de la PENITENCIA. En la Biblia se encontró un precedente: "Él, que todas las culpas perdona, que cura todas tus dolencias..., mientras tu juventud se renueva como el águila"33. Dice Guillaume Le Clerc: "El águila, que es capaz de regenerarse de esa manera, nos ofrece un buen y bello ejemplo, pues es de esa forma como debería actuar el hombre que quiere abandonar su viejo estado de maldad para hacerse un hombre nuevo". Philippe de Thaün: "El rejuvenecimiento del águila y el baño representan el bautismo en esta vida mortal". Según el Libellus de natura animalium, "debemos ascender hasta el fuego y aproximarnos al sol, o sea, acercarnos a Dios e ir hacia el fuego, esto es la penitencia; entonces se encienden las plumas, es decir, que los pecados serán perdonados a través de la penitencia tomada y asumida por los pecados; y entonces se zambulle en la fuente, es decir, en el bautismo, con lo que el hombre se hace nuevo". La versión griega del Fisiólogo dice: "Cuando el atuendo del hombre viejo te estorbe y los ojos de tu corazón se hayan entorpecido, busca el manantial que renueva la juventud, la fuente viva, que es la palabra de Dios... y vuela a las alturas hacia el sol

\footnotetext{
31 Etimologías XII, 7, 10.

${ }^{32}$ Mariño 1984, 49, 326; Roux, 102 y ss.

${ }^{33}$ Sal 103, 3-5. Ver Is 40, 31.
} 
de la justicia, Jesucristo, y despójate del hombre viejo con todas sus obras" 34 .

Esa renovación equivale a una resurrección, por lo que el águila se convierte en símbolo de CRISTO. Dice Covarrubias: "El águila significa a Cristo en razón de su excelencia entre los demás hombres, por ser hombre y Dios, como el águila entre las demás aves, por ser reina de ellas, y por tener el vuelo tirado con que bajó a encarnar en las entrañas de la Virgen María... De su Resurrección gloriosa se hace comparación al remozarse el águila".

Además del vuelo alto y la posterior zambullida, que significarían la renovación por la penitencia del fuego y por el bautismo del agua, el águila posee otra característica que se tomó como prueba de esa renovación: "Su rejuvenecimiento es considerado por los naturalistas como una simple renovación de su plumaje después de la muda" 35 .

Y como se renueva, hay que deducir que vive muchos años. El Fisió$\log o$ atribuido a San Epifanio asegura: "El águila, reina de las aves, recibe el nombre de su muy dilatada vida, ya que llega a vivir un centenar de años"36.

El águila también se renueva recortando su crecido pico contra una piedra. Tal creencia está inspirada en una leyenda egipcia que recoge Aristóteles y copia luego Plinio: Las águilas "no mueren ni por vejez ni por enfermedad, sino de hambre, pues la parte superior de su pico se alarga de tal manera que su curvatura le impide abrirlo"37.

En El Fisiólogo Griego ya aparece esa creencia transformada en una faceta más de la renovación: "Cuando envejece, su pico se curva y sus ojos se vuelven mortecinos, de modo que no puede ver, ni conseguirse el alimento. Entonces se eleva en los aires y, precipitándose ante el viento, se arroja contra una roca abrupta y se destroza el pico. Luego se baña en agua fría, y a continuación se remonta hacia los rayos del sol: en ese momento la opacidad desaparece de sus ojos y vuelve a ser joven". Lo mismo repiten Latini, El Fisiólogo atribuido a San Epifanio, el Bestiario de Oxford y el Bestiario Vadense. Covarrubias lo resume así: "El águila que está gastando el pico en una piedra significa una renovada juventud, por cuanto viene a no poder comer y envejecerse, por crecerle y encorvársele, hasta que usa de este remedio". Gervaise añade que Cristo es la roca en la que el águila afila su pico.

${ }^{34}$ Lo mismo en: El Fisiólogo atribuido a San Epifanio, El Fisiólogo Latino, Bestiario Toscano, Pierre de Beauvois, Bestiario Valdense, Guillaume Le Clerc, Borja 12.

${ }^{35}$ Hippeau 102. Ver Clébert.

${ }^{36}$ Ver Aristóteles IX, 32, 10 (619b).

${ }^{37}$ Aristóteles IX, 32, 15 (619a); Plinio X, 15. 
Las águilas ascienden con facilidad hasta grandes alturas y ahí se mantienen al acecho de sus presas a las que, "con su excepcional agudeza visual, detectan al atravesar los caminos y las zonas desnudas" 38 . En el libro de Job se hace referencia a esta característica: "Pone en la roca su mansión nocturna, su fortaleza en un picacho. Desde allí acecha a su presa, desde lejos la divisan sus ojos"39. También se hace mención de su portentosa vista en la Ilíada, en los Himnos homéricos, en la Historia natural, en una fábula de Odón, en Durayhim, en Latini, en Guillaume Le Clerc, etc. ${ }^{40}$.

Esa extraordinaria agudeza visual le vale su fama como medicina en los problemas oculares. Dice Eliano: "Si una persona que no ve bien mezcla bilis de águila con miel ática y unge los ojos con la mezcla, verá y adquirirá suma agudeza visual" ${ }^{41}$. Y también le vale el ser utilizada como símbolo de la VISTA ${ }^{42}$.

Es capaz de mirar directamente al sól. Así lo creían Aristóteles, Plinio, Eliano y otros autores antiguos ${ }^{43}$. "Cuentan también - dice San Isidoro- que mira de frente los rayos del sol sin cerrar los ojos" ${ }^{44}$. Dice Cantimpré: "Tiene una vista tan aguda y fina que puede mirar contra los rayos del sol sin parpadear". Pierre de Beauvais, Latini y el Bestiario Valdense también se hacen eco de la creencia. Dante muestra a Beatriz mirando al Sol como "jamás águila lo miró tan fijamente"

La creencia parece responder a un hecho cierto: el águila, como otras aves, posee en el ojo una membrana nictitante, túnica casi transparente que forma el tercer párpado, y que le permite fijar los ojos en el sol sin pestañear ${ }^{46}$. Y no sólo eso; el buitre - con el que bastantes veces se confunde al águila ${ }^{47}$ - "puede ser visto a menudo, sea en cautividad o silvestre, mirando al sol y abriendo al máximo sus grandes alas; y es de destacar que eso lo hace sólo cuando el sol brilla con fuerza, pues si una nube por pequeña que sea oculta el astro, el animal cierra inmediatamente sus alas y no las abre de nuevo hasta que el sol brille otra vez"48.

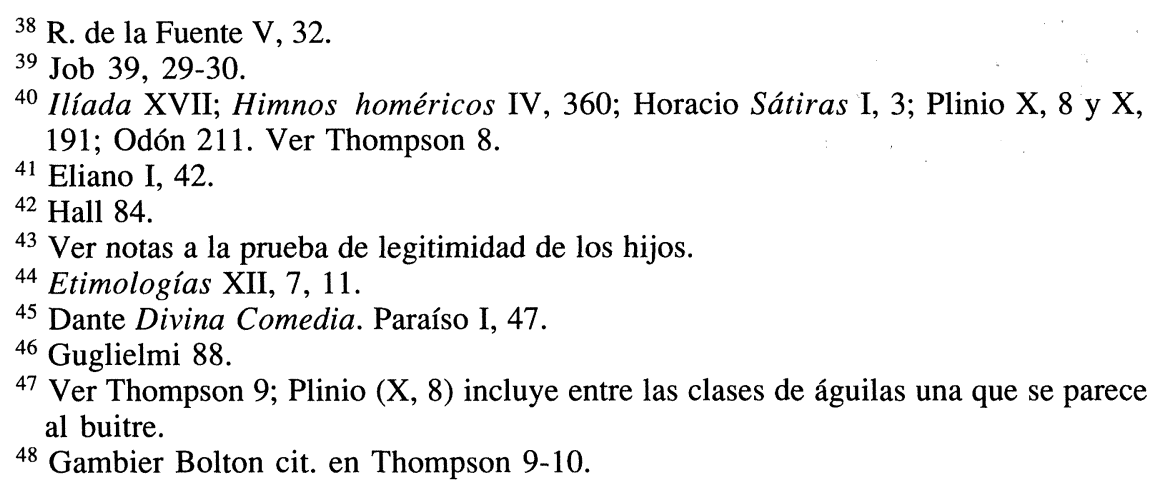

"CUADERNOS DE ESTUDIOS GALLEGOS", Tomo XXXIX, Fascículo 104, Santiago 1991. 
En función de esa característica, el águila es símbolo del JUSTO, que puede mirar directamente al Sol-Dios.Dice Heitor Pinto: "El águila, en cuanto vuela alto y tiene sus ojos fijos en el sol, significa el justo, contemplativo y humilde, que emplea el entendimiento en Dios" 49 . Y decía el Libellus de natura animalium: "Debemos ahora imitar con todas nuestras fuerzas esta propiedad, ya que debemos contemplar al sol, o sea, a Dios, con mirada recta" 50 .

En la capacidad para mirar directamente al sol se basa la prueba a la que somete a sus hijos: rechazará como ilegítimo a aquel de sus polluelos que no sea capaz de mirar directamente al sol. Aristóteles lo cuenta así: "El águila pescadora posee una vista muy penetrante, y fuerza a sus hijos, todavía sin plumas, a mirar al sol de frente; si uno rehúsa, lo golpea y lo vuelve hacia el astro; y si a uno de los dos polluelos, al mirar al sol, le lagrimean los ojos, lo mata y cría al otro" 51 . Plinio y Eliano copian al Estagirita ${ }^{52}$.' Más tarde lo harán San Isidoro ${ }^{53}$, Cantimpré, Philippe de Thaün, Brunetto, Guillaume Le Clerc, el Bestiario Toscano, el Bestiario de Oxford, etc. En el Libro de las utilidades de los animales se dice que tal prueba la realiza el macho para comprobar la fidelidad de su esposa: "Pone a prueba a su hembra con la vista de sus dos polluelos de forma que se encuentre con los rayos del sol, y si los resisten y mantienen firme la vista, entonces sabe que no lo ha traicionado y no los aparta".

¿En qué se basaron para creer en la existencia de esa prueba? Creo que en la reinterpretación de dos hechos comprobables. Por un lado tenemos que "los huevos del águila real pueden ser en ocasiones de colorido completamente diferente, como si perteneciesen a especies distintas" 54 . Esto fue la base para creer que podía tener hijos ilegítimos. La idea del castigo consiguiente se inspiró en el hecho de que uno de los dos polluelos del águila suele ser arrojado del nido, aunque no es la madre la autora de la fechoría: "Pasado el período de incubación nace el primer pollo, grande y cubierto de plumón blanco, y tres o cuatro días más tarde el segundo. Ocurre normalmente que el pollo que nace antes da muerte al más joven, por ser mucho más fuerte que él"55.

En el Bestiario de Pierre de Beauvais Dios hace con sus hijos como el águila con los suyos: "Dios considera como suyos los que creen perfectamente en Él, y no se preocupa de aquellos que no quieren reconocerlo,

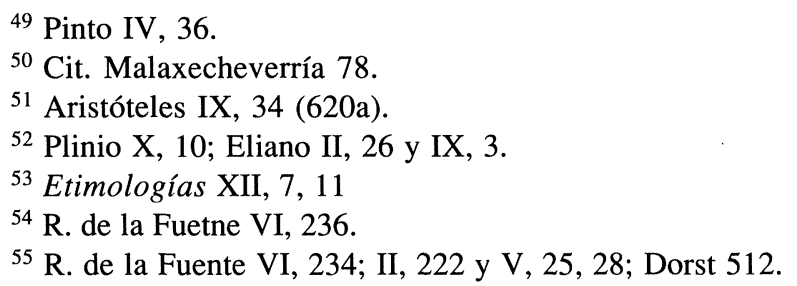


pues no los considera como hijos verdaderos". En el Bestiario Valdense los dos polluelos representan las obras del hombre: aquellas que no miren a Dios deben ser desechadas.

Se cree que el hijo expulsado del nido es recogido por otra ave. Lo dice Aristóteles: "Los que son expulsados gritan, y es entonces cuando el quebrantahuesos los toma a su cargo"56. Plinio: "Expulsan uno de sus aguiluchos para no tener que alimentarlo, pues en esa estación la comida les fue negada por la naturaleza... Pero los aguiluchos expulsados son recogidos por sus congéneres, los quebrantahuesos, que los crían con sus hijos" 57. Latini: "Sabed que un pájaro vil, la zarceta, viene a consumar el acto de orgullo del águila, pues acoge entre sus hijos al polluelo rechazado y lo cría como hijo". Para Cantimpré ese papel lo desempeña la foja ${ }^{58}$.

Las águilas cuidan y vigilan con muçho cariño a sus crías. "Generalmente la hembra monta guardia próxima al nido o permanece en él dando sombra y protección al aguilucho" 59 . Escribe Eliano: "El águila es, según parece, el más celoso custodio de sus polluelos. En efecto, si ve que alguien se aproxima a ellos, no consiente en que se marche sin castigo" 60. De la misma manera protege DIOS a su pueblo: "Como un águila incita a su nidada, revolotea sobre sus polluelos, así él despliega sus alas y le toma y le lleva sobre su plumaje"61. Y de la misma forma que el águila alimenta a sus hijos, así —dice Valeriano- el REY benigno y misericordioso se preocupa de sus súbditos.

Los padres enseñan a volar y a cazar a sus hijos. Para enseñarle a cazar, el águila culebrera "trae una culebra en el pico y, cuando está cerca, la levanta y la arrastra, repitiendo la maniobra cuanto sea necesario hasta que el joven la agarra"62. El águila calzada lleva a sus hijos en las excursiones de caza para que se familiaricen con la vida que han de llevar en adelante. Lo mismo - dice Rabano Mauro- hace CRISTO, "que no cesa de exhortar a sus discípulos en el ejercicio de las virtudes"63.

En el Libro de las utilidades de los animales se dice "que cuando está pesada y débil por la edad o ciega, la llevan los aguiluchos sobre su espalda, trasladándola de un lugar a otro para que busque caza, y así la cuidan hasta que muere".

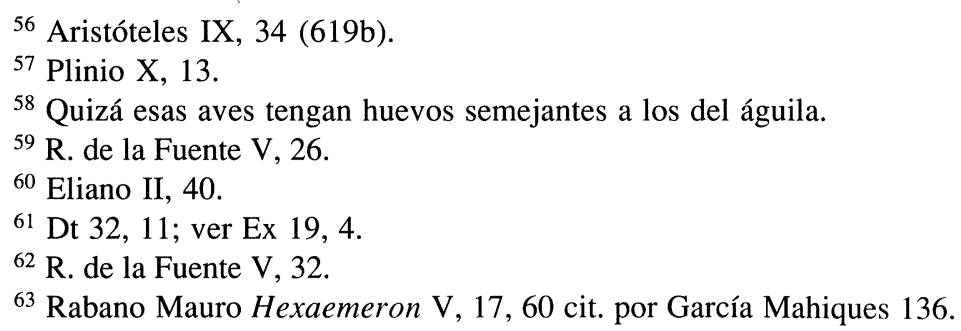


Vuela a gran velocidad ${ }^{64}$. En el libro de Job su velocidad se hace proverbial: "Mis días han sido más raudos que un correo..., como águila que cae sobre la presa" ${ }^{65}$. También en el de Jeremías: "Ligeros más que águilas sus corceles" 66 . Para Eliano "el águila es la más veloz de todas las aves"67.

Su increíble agilidad es la razón por la que aparece en la visión del carro de Yahveh del profeta Ezequiel: "En cuanto a la forma de sus caras, era una cara de hombre, y los cuatro tenían cara de león a la derecha, los cuatro tenían cara de toro a la izquierda y los cuatro tenían cara de águila" ${ }^{68}$. Estos cuatro seres vivientes son los cuatro Ángeles que presiden el gobierno del mundo físico. Son cuatro porque cuatro son los puntos cardinales. "Sus figuras (león, toro, hombre y águila) representan lo más noble, lo más fuerte, lo más sabio y lo más ágil que hay en la creación" ${ }^{6}$. En el Apocalipsis se repite la misma visión ${ }^{70}$. Sería San Ireneo el primero en interpretar esos cuatro vivientes como los cuatro Evangelistas. No siempre se identificó el mismo animal con el mismo Evangelista. Para San Ireneo el león era Juan, el toro Lucas, el hombre Mateo y el águila Marcos. Para Hipólito, San Agustín, Primasio y San Beda el toro era Lucas, el león Mateo, el hombre Marcos y el águila Juan. A San Epifanio y San Jerónimo se debe la interpretación que luego se impondría: el hombre es Mateo, el león Marcos, el toro Lucas y el águila Juan ${ }^{71}$. Para esa identificación se ądujeron las siguientes razones: "El hombre representa a Mateo porque su evangelio comienza con el árbol genealógico de Cristo; Marcos comienza con la voz que grita en el desierto, alusión al león; el toro, animal de sacrificio, es Lucas, cuyo evangelio comienza con el relato del sacrificio del sacerdote Zacarías; el águila, el ave que más se acerca al cielo en su vuelo, representa a Juan, cuya visión de Dios era la más próxima y se distinguía de la de los otros"72. Para el Beato de Liébana los cuatro animales, además de simbolizar los cuatro Evangelistas, representan cuatro momentos de la vida de Cristo: "Nació como hombre, murió como un ternero, resurgió como un león y subió a los cielos como un águila"73. En el Leccionario de Rabano Mauro los cuatro animales representan los cuatro

${ }^{64}$ R. de la Fuente VI, 236, 241.

65 Job 9, 25-26.

${ }^{66} \mathrm{Ez} 4,13$.

${ }^{67}$ Eliano I, 42.

${ }^{68} \mathrm{Ez} 1,10$.

${ }^{69}$ Nota de Biblia de Jerusalén a Ap 4, 6.

${ }^{70}$ Ap 4, 6.

${ }^{71}$ Enciclopedia de la Biblia.

72 Hall 102.

${ }^{73}$ Beato de Liébana 156; ver Alfonso X 1984, 117 ss.; Llompart 1984, 528.

"CUADERNOS DE ESTUDIOS GALLEGŐS", Tomo XXXIX, Fascículo 104, Santiago 1991. 
Evangelistas, esos cuatro momentos de la vida de Cristo y tienen además un tercer sentido: "Expresan las virtudes que necesitamos para salvarnos. Cada cristiano, en el camino de la perfección divina, debe ser un hombre, un toro, un león y un águila. Debe ser un hombre, porque el hombre es animal racional y porque sólo el que se adentra por el camino de la razón merece llamarse hombre; debe ser un toro, porque el toro es la víctima que se inmola en los sacrificios y porque el verdadero cristiano, renunciando a los placeres del mundo, se inmola a sí mismo; debe ser un león, porque el león es el animal valiente por excelencia y porque el justo, que ha renunciado a todas las cosas, no teme a nada en este mundo; debe ser finalmente águila, porque el águila vuela en las alturas y mira al sol sin bajar los ojos y porque el cristiano debe mirar de frente las cosas eternas" 74 .

El águila que forma parte de las procesiones de Corpus en el Levante español representa al evangelista San Juan ${ }^{75}$.

Por su extraordinaria rapidez y por ser feroz ave de rapiña se la clasificó como muy caliente y seca ${ }^{76}$. Especialmente cálido se considera su cerebro: "El cerebro del águila es tan cálido y da tanto calor - asegura Alberto el Grande - , que origina ilusiones fantásticas cerrando los conductos con sus humos y vapores"77. También sus plumas queman: "Los antiguos dicen que las plumas de las alas de las águilas - donde se produce mayor movimiento-, mezcladas con las de los otros pájaros, las queman y pican"78.

De su complexión muy cálida y seca se deduce que no beben. Dice Eliano: "Jamás el águila necesita agua". "Ningún ave de rapiña bebe ni orina"79. De su complexión también se deduce que forma parte de los animales bajo el influjo del Sol ${ }^{80}$; otras razones para asociarla con el sol son su condición de reina de las aves, pues el sol es rey de los astros; y su capacidad para mirar directamente sus rayos ${ }^{81}$.

Come carroña ${ }^{82}$; costumbre ya señalada por Aristóteles ${ }^{83}$. Dice el libro de Job: "Sus crías lamen sangre; donde hay muertos, allí está" 84 . Ese contacto con los cadáveres, así como el contacto con la sangre — como es

\footnotetext{
74 Mâle 59-60.

${ }^{75}$ Llompart 1984, 503 ss.

${ }^{76}$ Morin 222.

77 Alberto 78; Clébert 29.

${ }^{78}$ Alberto 100.

${ }^{79}$ Eliano II, 26 y IV, 20. Ver Thompson 10.

${ }^{80}$ Morin 222, Amasuno 23.

${ }^{81}$ Cárdenas 78-79.

${ }^{82}$ R. de la Fuente II, 228 y VBI, 236.

${ }^{83}$ Aristóteles IX, 32 (619a).

${ }^{84}$ Job 39, 30.
} 
propio de un ave de rapiña-, le valen su inclusión en la lista de animales impuros que aparece en el Levítico y el Deuteronomio ${ }^{85}$. "El águila dice Eliano-es ave de rapiña, vive de sus presas y es carnívora" 86 . Es un ENEMIGO peligroso: "Yahveh levantará contra ti una nación venida de lejos, de los extremos de la tierra, como el águila que se cierne" 87 . Es un TIRANO: "El águila, en cuanto que vive de la rapiña y desprecia a las demás aves, significa —dice Heitor Pinto- el tirano soberbio"88.

Por ave de presa y carroñera es uno de los animales en los que se encarna el DIABLO. Éste, aun cuando se muestre bajo aspecto humano, suele tener pico y garras de águila, es decir, aquellas partes del animal que representan su mortífera habilidad para la caza ${ }^{89}$. Dice elBestiario de Oxford: "El águila puede simbolizar a veces a los espíritus malignos rapaces de almas"90.

Como a cualquier animal de presa que ataque a los animales domésticos, se lo expulsa mediante exconjuros, como sucede en Galicia y en Asturias ${ }^{91}$.

El águila imperial, la real y la perdicera cazan y comen lagartos y culebras ${ }^{92}$. Incluso existe un águila, la culebrera, especializada en su caza: "Al ver una culebra se lanzan en picado, generalmente desde quince a treinta metros, hasta caer sobre ella, inmovilizándola con las garras... Enseguida, el águila aplasta con su pico la cabeza de la culebra hasta darle muerte"93. Dice Horacio: "Se la vio introducirse enemiga en los rediles y acometer briosa a las serpientes"94. Y Eliano: "El más intrépido de los animales, la serpiente, con sólo oír el rumor de sus alas, se introduce al instante en su cubil deseosa de hacerse invisible" 95 .

Por atacar a las serpientes se la considera enemiga del dragón. Lo dice muy claramente Aristóteles: "El águila y el dragón son dos especies enemigas, pues el águila se alimenta de serpientes" 96 . Plinio describe su combate: "El dragón busca los huevos de águila con habilidad destructo-

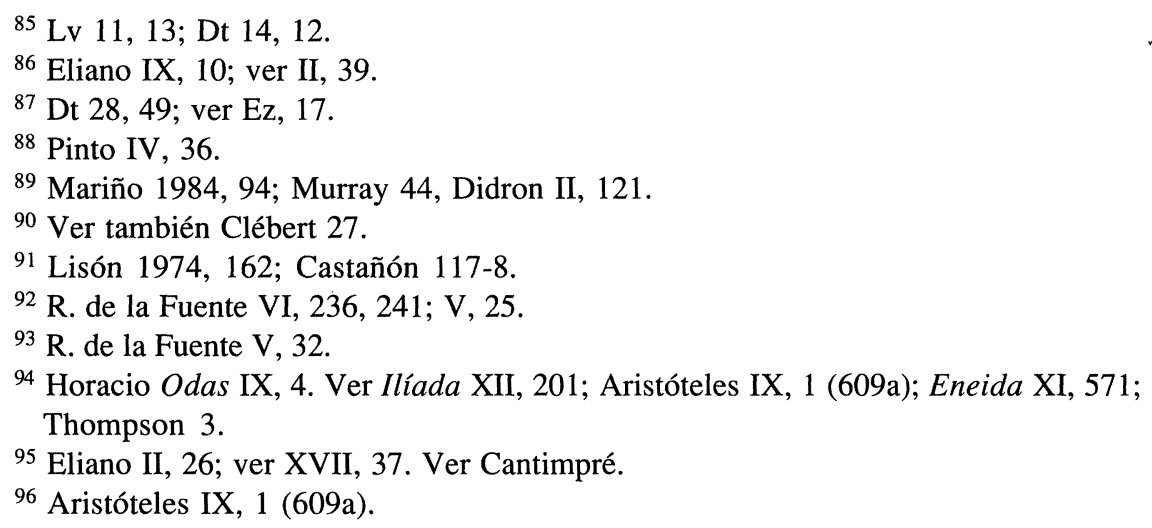


ra; el águila, por contra, lo coge en cualquier lugar que lo vea; pero el otro aprieta sus alas con múltiples nudos, enredándose de tal manera que caen juntos"97.

Puesto que la serpiente, por su mirada fija, representa el envidioso, "un águila enredada con una sierpe que le está picando en el pecho, es símbolo - según Covarrubias - de la VIRTUD contrastada y reprimida de la envidia". Y puesto que la serpiente es el Mal, el Diablo, el águila que la vence se convierte en símbolo de CRISTO ${ }^{98}$.

Según Plinio varias especies de águilas utilizan, para construir su nido, la piedra etites, que posee virtudes curativas siempre y cuando sea cogida en el nido del águila ${ }^{99}$. Laguna dice que efectivamente se las encuentra en su nido. Los antiguos creían que las águilas la llevaban al nido para facilitar la puesta. Dioscórides afirma que, atada al muslo de la parturienta, le ayuda a parir sin dolor. El mismo Dioscórides nos da la razón simbólica — dentro de la teoría de las signaturas - de ese empleo: "La piedra del águila suena en meneándose, por estar como preñada de otra piedra, que tiene dentro de sî"100. Plinio dice: "Resuena cuando se la sacude, encerrada como dentro de un útero" ${ }^{101}$. Efectivamente, la etites es una "concreción de óxido de hierro en bolas informes, compuesta de varias capas concéntricas de color amarillo y pardo rojizo, generalmente con un nódulo de la misma substancia suelto en lo interior de la bola"102. Un águila que vuela hacia su nido llevando una piedra significa - dice Covarrubias - al que FUNDA CASA con buenos cimientos y la asegura con firme mayorazgo".

Un águila es el atributo de SAN ANTONIN o Antolín porque intervino en el traslado de sus reliquias ${ }^{103}$.

El águila "aferra algunas veces tortugas terrestres, se remonta con ellas a las alturas y las suelta sobre cualquier roca; las recoge, las suelta de nuevo y así varias veces hasta que logra romper la gruesa coraza". Por lo tanto, "no es inverosímil el mito de que habla Plinio, según el cual Esquilo habría muerto al golpearle en la cabeza una tortuga dejada caer por un

\footnotetext{
${ }^{97}$ Plinio X, 17; Covarrubias dice lo mismo.

${ }^{98}$ Guerra 250. Cristo como águila que caza serpientes aparece en San Miguel de Iscar (Valladoilid), en la portada de Ripoll, Santa Eulalia de Lloraza (Asturias), Santa María de Uncastillo, Lemóniz, San Nicolás en Bari, cripta de Riechenberg, Chauriat. "La identificación del ave celeste con Jesucristo resalta en algunas miniaturas..".

${ }^{99}$ Plinio X, 12.

${ }^{100}$ Dioscórides V, 118; ver Covarrubias 869.

101 Plinio X, 12.

102 Diccionario Academia.

${ }^{103}$ Ferrando 46.
} 
águilla"104. En la fábula del águila y la tortuga se supone que la tortuga se mete voluntariamente en las garras del águila al pedirle que la lleve por los aires, con lo que se nos enseña que la estupidez de confiar en el enemigo se paga con la vida ${ }^{105}$. La fábula del águila y el escarabajo nos enseña que no debemos despreciar ni a los que parecen más insignificantes ${ }^{106}$. Se creía en una especial enemistad entre el águila y la garza, que es víctima de la rapaz ${ }^{107}$; entre el águila y el cárabo uralense —el gavilán nocturno de Plinio- ${ }^{108}$; y entre el águila y el cisne ${ }^{109}$.

${ }^{104}$ Alvarado VI, 184; la anécdota la cuenta Eliano VII, 16.

${ }^{105}$ Babrio 115, Aviano 2, Fedro III, 7; Thompson 15.

${ }^{106}$ Esopo 3, Covarrubias.

107 Aristóteles IX, 1 (609b).

108 Plinio X, 24 y nota. Ver Ferrer de Valdecebro 250, Solórzano 200.

${ }^{109}$ Covarrubias, Thompson 7.

"CUADERNOS DE ESTUdIOS GALLEGOS", Tomo XXXIX, Fascículo 104, Santiago 1991. 